\title{
A INFLUÊNCIA DAS LÓGICAS INSTITUCIONAIS NA ORGANIZAÇÃO ECONÔMICA DA AGRICULTURA FAMILIAR: UMA ANÁLISE NO SEMIÁRIDO NORDESTINO
}

\author{
THE INFLUENCE OF INSTITUTIONAL LOGIC ON ECONOMIC \\ ORGANIZATION OF FAMILY AGRICULTURE: AN ANALYSIS IN THE \\ NORTHEAST REGION
}

\section{LA INFLUENCIA DE LA LÓGICA INSTITUCIONAL EN LA ORGANIZACIÓN ECONÓMICA DE LA AGRICULTURA FAMILIAR: UN ANÁLISIS EN LA REGIÓN NORESTE}

\author{
Camila Marques Viana Silva ${ }^{1}$ \\ https://orcid.org/0000-0003-3773-5652 \\ Glauco Schultz ${ }^{2}$ \\ https://orcid.org/0000-0002-7569-7434
}

Submissão: 07/11/2020 / Aceito: 16/02/2021 / Publicado: 30/06/2021.

\section{Resumo}

Este trabalho pretende contribuir para a compreensão da relação entre a agricultura familiar e os mercados, através da mediação por organizações econômicas, objetivando fornecer, de maneira mais ampla, elementos para análise do papel que os arranjos organizacionais mobilizados pelos agricultores familiares exercem no desenvolvimento rural. Com base na premissa de que ao expandir suas relações e moldar seu campo organizacional a partir da rede de relações que estabelecem para acessar mercados, as Organizações Econômicas da Agricultura Familiar - OEAF são afetadas por uma ou mais lógicas institucionais presentes no ambiente no qual interagem, através da adoção de práticas materiais e simbólicas. Entender, portanto, como essas organizações sobrevivem diante da fragilidade de sua inserção econômica implica em conhecer quais lógicas as influenciam. Considerando a agricultura familiar como campo societal, foi identificada influência de dois tipos puros de lógica do sistema interinstitucional, a lógica do estado, a lógica da comunidade, uma variante da lógica de mercado, identificada como lógica do mercado alternativo e, por fim, uma lógica híbrida, a partir da combinação da lógica do estado e da lógica do mercado. Os resultados revelam que tais lógicas influenciam as práticas e símbolos nas OEAFs, moldando o comportamento organizacional.

Palavras-chave: Agricultura Familiar. Organizações. Mercado. Lógicas Institucionais.

\footnotetext{
${ }^{1}$ Doutora em Desenvolvimento Rural pela UFRGS/Programa de Pós-Graduação em Desenvolvimento Rural UFRGS. Analista Técnica de Políticas Sociais no Ministério da Agricultura, Pecuária e Abastecimento - MAPA - BRASÍLIA (DF), Brasil. E-mail: camis.mvs@gmail.com

${ }^{2}$ Doutor em Agronegócio pela UFRGS/Centro de Estudos e Pesquisas em Agronegócios - CEPAN. Docente no Programa de Pós-graduação em Agronegócio e do Programa de Pós-Graduação em Desenvolvimento Rural da UFRGS - UFRGS - PORTO ALEGRE (RS), Brasil. E-mail: 00107204@ufrgs.br
} 


\begin{abstract}
This work aims to contribute to the understanding of the relationship between family farming and markets, through mediation by promotion, aiming to provide, in a broader way, elements for analyzing the role that the organizational arrangements mobilized by family farmers play in rural development. Based on the premise that when expanding their relationships and shaping their organizational field based on the network of relationships they establish for access to markets, such as Family Farming Economic Organizations - OEAF are affected by one or more institutional logics present in the environment in the qualifier interact, through the adoption of material and symbolic practices. Understanding, therefore, how these associations survive survivors of the fragility of their economic insertion implies knowing which logics they influence. Considering family farming as a social field, the influence of two pure types of logic in the interinstitutional system was identified, the state logic, the community logic, a variant of the market logic, identified as the alternative market logic and, finally, a hybrid logic, based on the combination of state logic and market logic. The results reveal that such logics influence the practices and symbols at OEAFs, shaping organizational behavior.
\end{abstract}

Keywords: Family Farming. Organizations. Markets. Institutional logics.

\title{
Resumen
}

Este trabajo tiene como objetivo contribuir a la comprensión de la relación entre la agricultura familiar y los mercados, a través de la mediación de las organizaciones económicas, con el objetivo de aportar, de manera más amplia, elementos para analizar el papel que juegan los arreglos organizativos movilizados por los agricultores familiares en el desarrollo rural. Partiendo de la premisa de que al ampliar sus relaciones y dar forma a su campo organizacional a partir de la red de relaciones que establecen para acceder a los mercados, las Organizaciones Económicas de la Agricultura Familiar - OEAF se ven afectadas por una o más lógicas institucionales presentes en el entorno en el que interactúan, mediante la adopción de prácticas materiales y simbólicas. Comprender, por tanto, cómo estas organizaciones sobreviven ante la fragilidad de su inserción económica implica conocer qué lógicas las influyen. Considerando la agricultura familiar como un campo social, se identificó la influencia de dos tipos puros de lógica en el sistema interinstitucional, la lógica estatal, la lógica comunitaria, una variante de la lógica del mercado, identificada como la lógica alternativa del mercado y, finalmente, una lógica de mercado. lógica híbrida, basada en la combinación de lógica de estado y lógica de mercado. Los resultados revelan que tales lógicas influyen en las prácticas y los símbolos en las $\mathrm{OEAF}$, dando forma al comportamiento organizacional.

Palabras chave: Agricultura familiar. Organizaciones. Mercados. Lógicas institucionales.

\section{INTRODUÇÃO}

No Brasil, a agricultura familiar agrega um conjunto de categorias produtivas que se manifestam empiricamente de forma diversa e heterogênea com relação à mobilização de recursos para sua reprodução social, apresentando diferenças relevantes quanto às potencialidades e limites que enfrenta. Diante da precariedade estrutural em que se 
desenvolveu - combinando atividades agrícolas com outras formas de ocupação em atividades não agrícolas - uma das marcas da agricultura familiar é a constante necessidade de equilibrar a atividade mercantil com a garantia de consumo da família, já que, apesar de se tratar de um setor bastante diversificado quanto à disponibilidade de recursos, às formas de comercializar e à capacidade de geração de renda e acumulação, tem uma difícil relação com os mercados.

A luta por autonomia e sobrevivência frente às inúmeras pressões que se impõem sobre os sistemas locais e regionais de produção de alimentos é um dos principais desafios da agricultura familiar na atualidade (PLOEG, 2008; SCHMITT; MALUF, 2010). Além dos fatores decorrentes do padrão de desenvolvimento rural comumente denominado "modernizante" que, por si, tendem a excluir pequenos produtores menos capitalizados, as dificuldades resultam também de características inerentes às formas familiares de produção, marcadas por uma integração parcial aos mercados, o que lhes confere, de um lado, autonomia e, de outro, uma precária capacidade de sobrevivência no interior de sociedades capitalistas (ELLIS, 1988; PLOEG, 2008; ABRAMOVAY, 1992).

Para fazer frente ao conjunto de dificuldades e às constantes pressões exercidas pelo ambiente institucional, moldado para atender às demandas do sistema agroalimentar global, no que tange à escala, regularidade e padrões de qualidade e competitividade, os agricultores familiares recorrem a várias estratégias de produção, processos e práticas que configuram, segundo Pelegrini e Gazolla (2008), novidades produtivas. É o caso da diferenciação de produtos, a inserção em mercados ditos alternativos, e as práticas de cooperação por meio da organização em associações, cooperativas e redes.

A organização em cooperativas e associações, por si, não é propriamente uma novidade na agricultura familiar, uma vez que estas sempre se constituíram em importantes mecanismos na mediação a relação dos agricultores com os mercados e na promoção, em alguma medida, do acesso a financiamentos, tecnologias, conhecimento e assistência técnica. De modo geral, tais organizações refletem a heterogeneidade que marca a agricultura familiar no Brasil, o que pode ser observado a partir da diversidade de formatos que se organizam conforme estruturas tradicionais de governança ou em arranjos interorganizacionais e em suas em distintas capacidades de inserção econômica.

Neste sentido, o presente trabalho adota o conceito de Organizações Econômicas da Agricultura Familiar - OEAF para descrever os arranjos organizacionais que os agricultores 
familiares mobilizam para intermediar a relação com os mercados. Incluem-se, portanto, as cooperativas singulares e centrais, as associações, as microempresas rurais e as redes de comercialização que, nesse contexto, cumprem o papel de articular várias OEAFs em torno de estratégias comuns de acesso aos mercados, podendo se comportar ora como espaço de formação, troca de informação e construção de sociabilidades, ora como o próprio agente econômico.

No intuito de aprofundar os estudos sobre as OEAFs no Brasil, para além do papel das organizações coletivas como um importante mecanismo para a promoção da dinamização econômica e social dos territórios rurais, este trabalho enfoca o movimento empreendido pelos agricultores familiares no sentido de se organizarem para acessar canais de comercialização alternativos e, de tal modo, viabilizar a comercialização de produtos não convencionais, a partir da adoção de determinadas práticas sociais.

Ao expandir suas relações e moldar seu campo organizacional a partir das redes relacionais que estabelecem no processo de inserção econômica, as OEAFs são afetadas por uma ou mais lógicas institucionais presentes no ambiente no qual interagem, por meio da adoção de práticas materiais e construções simbólicas. Entender, portanto, como tais organizações sobrevivem diante da fragilidade dessa inserção, implica em conhecer quais são as lógicas que as influenciam. Dessa forma, a noção de lógica institucional é adotada por considerar os aspectos do campo material e simbólico das organizações, fornecendo um novo olhar sobre a relação dos agricultores com os mercados, a partir da compreensão de como se moldam suas práticas de gestão nos ambientes macro e microinstitucional.

Assim, com base na problemática exposta e na premissa da existência das lógicas institucionais, a presente pesquisa tem como objetivo compreender como as orientações de lógicas institucionais se apresentam nas estratégias de acesso ao mercado, a partir das práticas e símbolos adotados pelas OEAFs, ao longo da sua trajetória, apresentando como caso de estudo duas OEAFs do semiárido nordestino.

\section{PROCEDIMENTO METODOLÓGICO}

Haja vista os objetivos propostos e as exigências metodológicas da lógica institucional, que pressupõe investigar aspectos da realidade não-quantificáveis, a pesquisa foi realizada a partir de uma abordagem qualitativa, com caráter descritivo, que trabalha com 
o universo de significados, motivos, aspirações, crenças, valores e atitudes, correspondendo a um espaço mais profundo das relações, dos processos e dos fenômenos que não podem ser reduzidos à operacionalização de variáveis (MINAYO, 2001). Quanto aos meios para a realização, adotou-se como a estratégia principal o estudo de caso, com ida a campo, pois o objeto analisado enquadra-se na situação em que os limites entre o fenômeno e o contexto investigado não são claramente percebidos.

Dentro desta perspectiva foram selecionados casos que representam uma contribuição significativa para compreensão do objeto proposto, obedecendo aos seguintes critérios previamente estabelecidos:

1) possuir um arranjo organizacional inovador;

2) atuar com produção agroecológica/orgânica e/ou oriunda do extrativismo; e

3) acessar mercados alternativos.

Para escolha dos casos, realizou-se um levantamento inicial das OEAFs que atendessem, simultaneamente, os quatro critérios estabelecidos pela pesquisa, sendo identificados cerca de 50 OEAFs, entre redes e cooperativas (centrais e singulares) de todas as regiões do país. Para o aprofundamento, delimitou-se a análise à região Nordeste, que, além de abrigar metade dos agricultores familiares do país, concentra parte significativa das organizações identificadas com base nos quatro critérios estabelecidos e, preferencialmente, localizadas no Semiárido.

Diante disso, foram selecionadas a Coopercuc, no Território Sertão do São Francisco, localizado na região norte do estado da Bahia, e a Rede Xique Xique, com sede na cidade de Mossoró e atuação em vários territórios do Rio Grande do Norte. Essas organizações não só atenderem aos critérios estabelecidos, mas também possuem uma ampla rede de parceiros, têm representatividade em vários fóruns deliberativos ou de discussão sobre agricultura familiar e combinam diversas estratégias de organização, produção e acesso a mercados, refletindo a complexidade das OEAFs.

Quanto aos dados e suas técnicas de coleta, foram utilizadas múltiplas fontes de dados, primários e secundários. A coleta de dados secundários iniciou-se antes da pesquisa de campo, na qual foram consultados trabalhos acadêmicos sobre a Coopercuc, a Rede Xique Xique e seus respectivos territórios de atuação, com o objetivo de familiarizar-se com os casos e seu contexto social e identificar as lacunas e eventuais contribuições desses trabalhos para a pesquisa em questão. Para subsidiar a análise dos casos e fornecer elementos que 
ajudam a entender a realidade das OEAFs e a conformação do ambiente institucional no qual se inserem, recorreu-se a dados gerais sobre estas organizações relacionados à gestão e acesso às políticas de crédito e comercialização, adotando o recorte da DAP. Assim, as principais fontes consultadas foram: a base de dados da DAP jurídica; relatórios do Programa Mais Gestão; a Matriz de Dados do Crédito Rural; relatórios de execução do PAA e PNAE 3 . Durante o campo, foram também coletados dados secundários das OEAFs pesquisadas através de seus documentos oficiais, como as atas de reuniões, estatutos, planejamentos, sítios eletrônicos e redes sociais, manuais, relatórios técnicos e materiais de divulgação. A pesquisa de campo foi realizada entre os meses de novembro de 2014 e maio de 2016, considerando a participação em eventos e o período de imersão nas organizações, no qual a pesquisadora acompanhou durante 15 dias o cotidiano da Coopercuc e da Rede Xique. A coleta de dados, no entanto, se estendeu até junho de 2017, a partir de outros meios, como contatos telefônicos com membros das organizações e acompanhamento das ações através de suas mídias sociais.

Os dados primários foram coletados por meio da observação direta e entrevistas semiestruturadas realizadas durante o campo. Com o objetivo de orientar o diálogo entre entrevistador e entrevistado, foram elaborados três tipos de roteiros, fundamentados em elementos do referencial teórico, para: a) membros da diretoria e área técnica; b) agricultor associado; e c) entidade parceira.

Como plano analítico foram utilizadas a técnica análise de conteúdo (BARDIN, 1979), a partir da triangulação de dados, de acordo com prescrição da lógica institucional que privilegia os métodos interpretativos de análise dos dados. Análise de conteúdo busca compreender o pensamento do sujeito através do conteúdo expresso no texto. Tal modalidade de análise "consiste em descobrir os núcleos de sentido que compõem uma comunicação cuja presença ou frequência signifique alguma coisa para o objetivo analítico visado", segundo Minayo (2007, p. 316).

\footnotetext{
${ }^{3}$ As informações referentes à DAP Jurídica, ao Programa Mais Gestão e ao PNAE foram solicitadas diretamente às áreas responsáveis por tais programas na SEAD. Os dados do PAA foram acessados através do PAA-Data disponível em: 〈https://aplicacoes.mds.gov.br/sagi/paa/visi_paa_geral/pg_principal.php?url=abertura > Já as informações do crédito rural estão disponíveis no endereço: <http://www.bcb.gov.br/ptbr/\#!/c/MICRRURAL/>.
} 


\section{RESULTADOS E DISCUSSÃO}

Tendo como pano de fundo as mudanças no ambiente institucional da agricultura familiar brasileira nas últimas décadas, observou-se a trajetória histórica, os aspectos do ambiente técnico representados por elementos da estrutura e dinâmica organizacional das OEAFs pesquisadas, além das estratégias de acesso a mercados adotadas, permitindo assim, a identificação das práticas materiais e simbólicas que dão significado à vida social dessas organizações, possibilitando a compreensão do conteúdo das lógicas institucionais no nível micro. A partir desta análise, tomando a organização como unidade de análise central, observou-se elementos do ambiente institucional e do campo organizacional que envolvem e condicionam as relações sociais, representando, nessa ordem, os níveis analíticos macro e meso.

\section{Aspectos do ambiente institucional e organizacional da Coopercuc e Rede Xique Xique}

A Cooperativa Agropecuária Familiar de Canudos, Uauá e Curaçá - Coopercuc, atua com frutas nativas do bioma caatinga e está localizada ao norte do estado da Bahia, mais precisamente no território rural Sertão do São Francisco, na região do Semiárido. Os municípios de Uauá, Curaçá e Canudos, onde a cooperativa atua, refletem a realidade da região semiárida nordestina, marcada pela pobreza, concentração de terras, seca e falta de acesso à água. Uma característica marcante dessa região é a presença das chamadas Comunidades de Fundo (ou Fecho) de Pasto, que são reservas de pastagem em terras públicas utilizadas para o pastoreio comunitário. Os Fundos de Pasto são reconhecidos oficialmente pela Política Nacional de Povos e Comunidades Tradicionais, como uma forma de manejo e administração dos recursos naturais, cuja certificação está atrelada à organização em associações, implicando em novos desafios para os agricultores familiares.

No caso das comunidades estudadas, além do uso para pastoreio, o Fundo de Pasto é também onde ocorre a coleta do umbu (Spondias tuberosa) e do maracujá-do-mato (Passiflora cincinnata Mast.), espécies endêmicas da Caatinga. Carro-chefe da Coopercuc, o umbu tem sido utilizado em vários tipos de preparações, como sucos, doces, geleias, compotas e sorvetes. Já o maracujá-do-mato, pouco explorado comercialmente, é utilizado pela cooperativa basicamente para a fabricação de geleias. 
Em termos de estrutura organizacional, a Coopercuc segue formalmente um modelo tradicional, respeitando as exigências da legislação vigente, sendo composta por: Assembleia Geral dos cooperados; Conselho Fiscal e Diretoria Executiva que se desmembra em presidência, tesouraria e secretaria executiva. Já em relação a estrutura física da cooperativa, até 2016, em um mesmo terreno, funcionava a sede administrativa, a fábrica central, um depósito para insumos e estoque, um pátio que funcionava de garagem e recepção de produtos, além de um escritório, anexo à fábrica, onde funcionava o setor de produção. Em 2017, a Coopercuc passou a funcionar na nova Fábrica Central em Uauá, resolvendo parte do problema com espaço entre os setores e, portanto, proporcionando uma divisão melhor entre eles.

Quanto aos setores técnicos e de gestão, apesar de ter uma rotina de procedimentos bem organizada, a gestão administrativa e financeira da cooperativa apresenta deficiências do ponto de vista do monitoramento, controle e avaliação. A área comercial tem uma divisão de atribuição mais bem definida entre os técnicos. A divisão, nesse caso, se dá por tipo de mercado acessado e não por atividade. Em cada subárea, portanto, o técnico é responsável por quase todos os processos, desde a relação direta com o setor de produção e com os próprios associados, elaboração de projetos de venda para os programas governamentais, faturamento, controle de pagamentos e até emissão de notas.

Em relação ao quadro social, a cooperativa que iniciou da experiência de um grupo de 20 pessoas e que foi fundada por 44 agricultores, atualmente conta com um quadro social de 271 cooperados, apresentando, portanto, um crescimento de mais de 500\%, sendo o período de 2008 a 2012, no qual a cooperativa praticamente dobrou de tamanho, coincidindo com sua fase de expansão no mercado interno. Do total de cooperados, aproximadamente $67 \%$ são mulheres e 33\%, homens. Destes, atualmente $82,7 \%$ possuem DAP física. Os 12,3\% que não possuem a declaração, em sua maioria, estão trabalhando em outras áreas ou se mudaram para grandes centros em busca de outras oportunidades.

No que tange a produção, a Coopercuc produz doces cremosos e de corte, geleias (também na versão light) e compotas que compõem a linha GRAVETERO. Em 2015, foram cerca de 160 toneladas de produtos produzidos nas comunidades e unidade central. Cada comunidade tem um grupo responsável pela produção nas minifábricas. Cada grupo, por sua vez, elege um coordenador que organizam os grupos de coleta, o cronograma e processo de produção nas unidades de beneficiamento. Na fábrica central, são produzidas as geleias, 
compotas e os doces. Além das frutas nativas, são utilizadas também frutas como goiaba, banana, manga e maracujá comum, oriundas dos quintais das propriedades familiares. A cerveja de Umbu, lançada no Festival do Umbu de 2015, foi desenvolvida, em caráter experimental, por uma cervejaria artesanal de Belo Horizonte. A partir da grande aceitação do público, a cooperativa resolveu apostar na produção e escala comercial. A cerveja tem sido uma grande aposta da cooperativa, apesar de ser um produto que absorve pouca matéria prima, tem bastante apelo comercial.

Nos últimos anos, a estratégia comercial da cooperativa se voltou mais para o mercado interno, comercializando para o PAA e PNAE, para a rede Pão de Açúcar através do programa Caras do Brasil, em feiras e eventos promocionais, além das lojas e empórios especializados em produtos saudáveis/naturais/orgânicos. Mais da metade dos valores comercializados pela Coopercuc corresponde às vendas para os mercados de compras governamentais, sobretudo para o PAA, seguido das vendas para o varejo que incluem os supermercados, as lojas e as vendas através das redes de comercialização. Em terceiro lugar, representando $10 \%$ das vendas, estão as feiras e eventos promocionais.

Em relação a Rede Xique Xique de Comercialização Solidária - RXX esta atua no estado do Rio Grande do Norte e se constitui através de um complexo arranjo que envolve empreendimentos formais e informais, em sua maioria, constituídos por agricultores familiares, unidos pelos princípios da Economia Solidária, Agroecologia e feminismo. Com sede em Mossoró, a Rede Xique Xique se organiza a partir de 19 núcleos municipais distribuídos nos territórios Assu-Mossoró, Mato Grande, Sertão do Apodi e Terras Potiguaras. Destes, 12 estão consolidados (Mossoró, Tibau, Baraúna, Grossos, Apodi, Janduís, Governador Dix-Sept Rosado, Messias Targino, São Miguel do Gostoso, Serra do Mel, Felipe Guerra, Upanema e Pendências) e 07 em fase de estruturação (São Rafael, João Câmara, Pureza, Jandaíra, Natal e Parnamirim).

Atualmente a RXX possui cerca de sessenta grupos articulados, sendo metade deles constituídos apenas por mulheres, beneficiando diretamente cerca de 600 produtores e indiretamente mais de 2.000 pessoas através das ações que executa por meio de convênios. A produção dos núcleos é bastante diversa e inclui produtos hortícolas, doces e geleias, mel, castanha de caju, mariscos, polpas de fruta e artesanatos. O trabalho da rede consiste em promover a organização e articulação dos núcleos por meio de um conjunto de atividades de formação, práticas agroecológicas, intercâmbios, comercialização da produção e apoio à 
organização de feiras locais. Para isso, conta com diversos parceiros e possui alianças estabelecidas com movimentos sociais vinculados aos seus eixos de atuação.

Para representá-la institucionalmente, foi criada uma associação (com mesmo nome) como instância jurídica para apoio operacional. Após muitas discussões, foi criada a Cooperativa de Comercialização Solidária - Cooperxique, em 2012. Para viabilizá-la economicamente, as vendas da loja e da feira semanal, ambas na sede da Rede, passaram ser contabilizadas via cooperativa. A partir de 2013, começaram a acessar, de maneira tímida, o PNAE, com pequenos projetos de venda para escolas da rede estadual em Mossoró e em 2015, tiveram o primeiro projeto de fornecimento para o PAA aprovado.

O desenho organizacional da Rede foi elaborado com base em sua carta de princípios, que privilegia a horizontalidade das relações e o protagonismo das mulheres. Visando se afastar, portanto, das estruturas formais hierárquicas. Para dar conta disso, se organiza a partir de uma complexa estrutura, e exige a participação mínima de $50 \%$ de mulheres em todas as instâncias. Já a Cooperxique possui um organograma que se aproxima das estruturas tradicionais de organização, sendo um pouco mais hierárquica comparada à Associação. A cooperativa foi registrada com 22 sócios indicados pelos núcleos, pois o conselho gestor da Rede avaliou que seria melhor começar com um quadro de sócios pequeno. Em 2015, foram disponibilizadas 100 cotas-parte para aqueles membros que quisessem se cooperar, respeitando o princípio da livre adesão, mas, além das 22 já cooperadas, apenas 11 agricultores se interessaram, mesmo a criação da cooperativa sendo sido uma demanda dos núcleos.

Por contar com uma equipe reduzida, não há divisão por setores específicos, mas por tarefas. A dependência dos projetos para pagamento dos técnicos, faz com que o quadro de pessoal atuando na rede seja bastante flutuante.

Os núcleos da Rede possuem produção bem diversifica refletindo a variedade dos grupos que os compõem. Há também grupos que prestam serviços de alimentação. A produção agroecológica é um dos critérios para participação na Rede, mas a certificação não é exigida. A rede acredita no controle social feito pelos próprios núcleos. Com relação às atividades não agrícolas, destaca-se a produção de artesanato que está presente em todos os núcleos. Os produtos são feitos a partir de diversos materiais, como biscuit, pena, conchas, palhas, e etc. 
Quanto a estratégia de mercado, a Rede se estrutura a partir de duas grandes estratégias. A primeira consiste na articulação dos núcleos para que criem seus próprios espaços de comercialização, sejam, eles, feiras ou pontos fixos, como forma de promover o acesso autônomo dos agricultores aos mercados, estimular o contato mais direto com os consumidores e dinamizar a economia dos municípios, gerando não apenas renda, mas também trabalho, principalmente para as mulheres rurais que, ao se envolverem no processo de comercialização, tem mais chances de se empoderarem.

A segunda envolve a estruturação da própria rede como um canal de comercialização, conforme pensado em seu desenho original. Para tanto, conta com o suporte da Cooperxique. O objetivo principal, nesse caso, é proporcionar o acesso a outros mercados de modo a absorver o excedente de produção dos núcleos. Ademais, com uma fonte de receita própria, a RXX visa diminuir a dependência de recursos externos para continuar promovendo o trabalho de organização e suporte às feiras realizadas pelos núcleos. Atualmente, a RXX possui quatro pontos fixos de comercialização.

No caso do PNAE, em 2013 e 2014, a Cooperxique começou, de maneira tímida, a participar de algumas chamadas públicas das redes estadual e municipal de ensino de Mossoró, Recentemente, com o foco voltado novamente para a comercialização, a Cooperxique concorreu às duas chamadas publicadas pelo IFRN para aquisição de gêneros alimentícios através do PNAE e do PAA, na modalidade Compra Institucional. A cooperativa foi selecionada para fornecer em três campi do instituto, a partir do segundo semestre de 2017.

\section{Configuração dos campos organizacionais e a influência das lógicas institucionais}

Com base no pressuposto básico da teoria neoinstitucional, as OEAFs só podem ser compreendidas a partir da relação com seu ambiente, representado pelos elementos institucionais (estruturais e simbólicos) e pelas demais organizações que compõem os campos organizacionais nos quais estão insertas. Conforme observado por meio da análise e descrição do ambiente institucional da Coopercuc e da Rede Xique Xique, sua constituição e estruturação só foram possíveis graças à atuação de atores organizacionais comprometidos com o desejo de mudança social em seus respectivos territórios. Ao longo das trajetórias, 
essas organizações tiveram seus campos ampliados pela soma de outros atores e relações que, atualmente sustentam sua legitimidade e sobrevivência.

$\mathrm{Na}$ Coopercuc, é a partir dos resultados positivos, gerados pelo apoio de organizações como o Slow Food, que outros atores começam a se aproximar da cooperativa, como os órgãos governamentais, Sebrae e Embrapa. Com base nas caraterísticas de sua estrutura descentralizada de produção (figura 1), na agregação de valor às frutas nativas da Caatinga através da agroindustrialização e a certificação orgânica e de comércio justo, a Coopercuc torna-se referência de convivência com o semiárido e um ator estratégico no território, fazendo parte dos conselhos de desenvolvimento rural, dos colegiados territoriais e demais instâncias de participação.

Já em relação a Rede Xique Xique, apesar de ter sofrido algumas variações ao longo dos anos, com mudanças na sua própria constituição, no foco de atenção e nas parcerias mobilizadas, a configuração atual do campo organizacional da Rede não difere substancialmente de quando foi criada.

A configuração do campo organizacional da RXX reflete claramente seus princípios da Agroecologia, do feminismo e da Economia Solidária que norteiam suas ações. Ao longo da trajetória da organização, no entanto, e possível notar diferenças na importância que cada um deles assume, ora prevalecendo um sobre os outros, ora se somando. Verifica-se também como a priorização dada aos processos de articulação em detrimento da comercialização influenciou o desenho do campo, caracterizado pela presença significativa de movimentos sociais e espaços de representação. 


\section{Figura 1 - Representação gráfica do campo organizacional da Coopercuc}

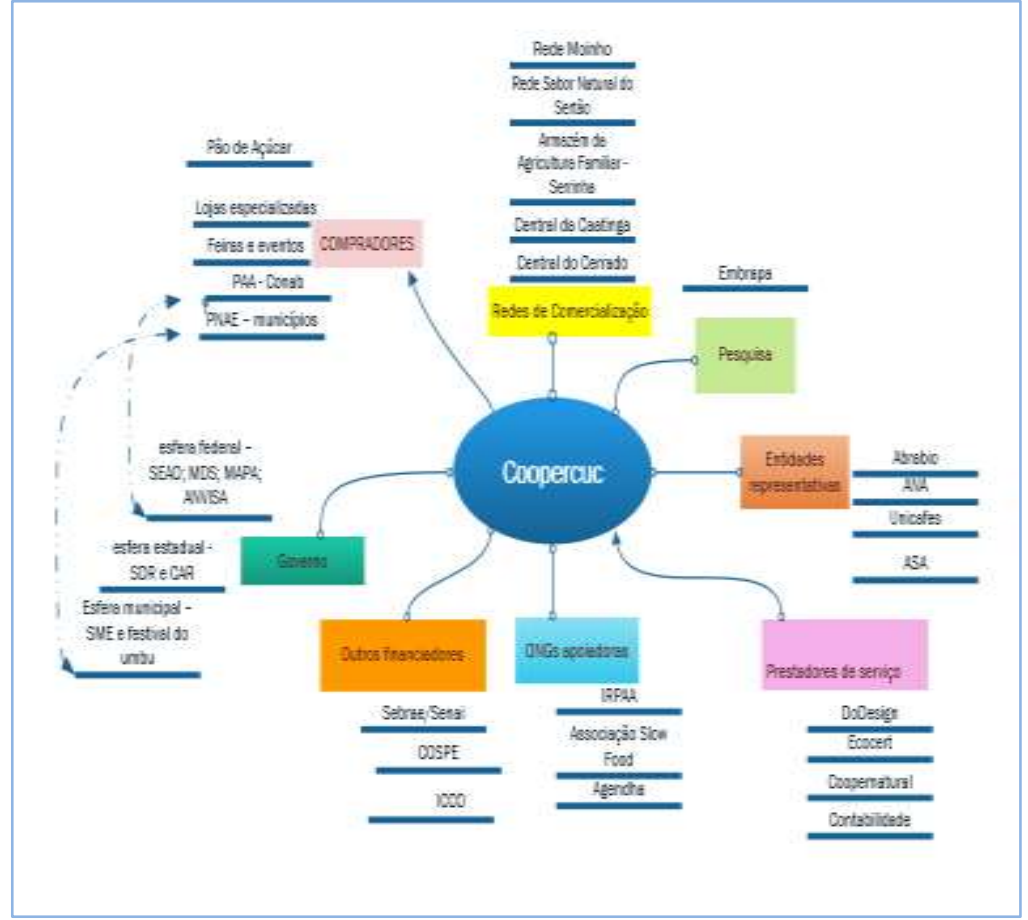

Fonte: pesquisa de campo, 2016. Elaborada pelos autores.

Figura 2 - Representação gráfica do campo organizacional da Rede Xique Xique

Fonte: pesquisa de campo, 2016. Elaborada pelos autores. 
Como pode ser observado na figura anterior, o movimento da Economia Solidária se estende em várias categorias, desde o governo e redes de comercialização, até as entidades e espaços de representação. O papel estratégico da RXX em cada uma dessas instâncias, a torna um ator central também no campo da Economia Solidária como cogestora das políticas públicas do setor.

Ainda na esfera da representação, destaca-se a presença da RXX em vários espaços de participação nas políticas públicas como conselhos, colegiados e câmaras técnicas (CMDRS, CIAT, Consea), vinculados aos seus eixos de atuação. A cogestão das políticas acontece tanto por meio da atuação nos espaços de participação democrática, como por meio da sua execução direta, destacando-se mais uma vez as ações no campo da Economia Solidária, no qual desenvolve a maioria dos projetos.

No âmbito dos mercados, a priorização da RXX em favorecer os canais mais diretos de comercialização, como as feiras, os pontos de venda e os grupos de consumo, possibilitam a aproximação entre produção e consumo, o que torna os consumidores finais atores estratégicos na configuração dos campos, ainda que estes ajam de maneira desarticulada entre si.

Verifica-se que a Coopercuc e a Rede Xique Xique apresentam campos organizacionais com uma configuração parecida, sustentada por um conjunto de parcerias com instituições governamentais e não governamentais, instituições de pesquisa, instâncias de representação e participação, movimentos sociais e redes ou centrais de comercialização/articulação, além de compradores e prestadores de serviço. Diferente do que se observa ao analisar setores industriais convencionais, onde o papel de atores como fornecedores e competidores tem maior relevância, nos casos analisados estes exercem pouca influência na dinâmica do campo, apesar de afetarem as o cotidiano (fornecedores) ou relação com os mercados (competidores) das OEAFs.

Entretanto, especificidades do contexto em que se desenvolveram e das organizações envolvidas no campo, assim como a intensidade das relações com elas estabelecidas, tornam as OEAFs mais diferentes do que semelhantes, contradizendo a tese do isomorfismo, central à teoria neoinstitucional, segundo a qual as organizações, em um dado campo, tendem à semelhança ao se conformarem a práticas e valores socialmente legitimados na busca por sobrevivência. 
No que tange a influência da lógica institucional, o presente trabalho parte da tipologia de ordens institucionais, ou setores societais proposta por Friedland e Alford (1991) e adaptada por Thornton, Ocasio e Lounsbury (2012) que identifica o Estado, o mercado, a comunidade, a religião, a família, as profissões e a corporação como fontes de racionalização. O conteúdo das lógicas institucionais em cada um deles é dado, no entanto, não apenas pelas fontes de legitimidade, mas também pela identidade que possibilita a conexão cognitiva, normativa e emocional vivida pelos membros de um grupo social por causa de seu status comum percebido com outros membros; e fontes de autoridade. Os tipos ideiais criados para identificação das lógicas, portanto, partem desses e de outros elementos que variam conforme o contexto analisado e o que se pretende observar.

Com base na análise dos casos, consubstanciada pelos aspectos contextuais e institucionais do ambiente em que se situam, foi identificada a influência das lógicas institucionais do mercado, Estado e comunidade, além de híbridos entre elas e variantes. Quanto aos demais tipos, ressalta-se que aspectos da lógica da religião e da família podem ser observados nos tipos de lógica comunitária e que não se identificou influência das lógicas da corporação e das profissões.

Nos campos organizacionais analisados, a lógica do mercado alternativo é fortemente influenciada por princípios ideológicos do movimento da Economia Solidária e da Agroecologia, moldando as práticas, no campo da produção e da gestão, e também os discursos adotados. Esta difere da lógica original, principalmente quanto às fontes de identidade e legitimidade, e quanto à alocação da atenção e das estratégias a serem adotadas pelas organizações.

A principal fonte de autoridade na lógica de mercados alternativos refere-se ao ativismo e militância nos movimentos mencionados. Isso explica, por exemplo, como a Rede Xique Xique, que - analisada à luz dos critérios econômicos de eficiência e lucro, não seria considerada um empreendimento de sucesso -, tornou-se uma referência quando se trata de redes solidárias e circuitos curtos de comercialização.

Neste sentido, a partir de um quadros-síntese onde consta o apontamento dos principais eventos que marcaram a trajetória da Coopercuc e da Rede Xique Xique, identifica-se quais orientações de lógicas institucionais prevaleceram em determinados períodos e como cada uma influenciou as estratégias de mercado adotadas, a estrutura e o 
comportamento organizacional a partir da adoção de práticas materiais e simbólicas ou da transformação daquelas existentes.

No quadro abaixo, segue o exemplo da Coopercuc com destaque para alguns eventos históricos, as lógicas institucionais identificadas como marcantes e as práticas materiais e simbólicas que dão conteúdo e são reflexos de tais lógicas. 


\section{Quadro 1 - Eventos históricos, lógicas institucionais e práticas materiais e simbólicas que marcaram a trajetória da Coopercuc $(1986$ - 2017)}

\begin{tabular}{|c|c|c|c|}
\hline Período & Acontecimentos/eventos & Resultados e LI & $\begin{array}{c}\text { Práticas Materiais e } \\
\text { Simbólicas }\end{array}$ \\
\hline $\begin{array}{c}1986- \\
2002\end{array}$ & $\begin{array}{l}\text { Trabalho de base da igreja católica - } \\
\text { organização comunitária e formação de } \\
\text { lideranças } \\
\text { IRPAA: convivência com o semiárido, geração } \\
\text { de renda } \\
\text { Grupo "Unidos do Sertão" com } 20 \text { agricultoras. } \\
\text { Comercialização do doce de umbu na feira de } \\
\text { Uauá } \\
\text { Ampliação dos grupos produtivos nas } \\
\text { comunidades }\end{array}$ & $\begin{array}{l}\text { Formação política dos } \\
\text { agricultores Perspectiva } \\
\text { de convivência com o } \\
\text { semiárido. Umbu como } \\
\text { fonte de renda } \\
\text { Constituição do grupo } \\
\text { produtivo } \\
\text { (comunidade) }\end{array}$ & $\begin{array}{c}\text { - realização de mutirões } \\
\text { - proximidade entre os } \\
\text { cooperados } \\
\text { - interesses comuns } \\
\text { - participação conjunta em } \\
\text { atividades sociais, políticas } \\
\text { e religiosas } \\
\text { - conhecimento partilhado } \\
\text { uniforme entre os membros } \\
\text { - tomada de decisão } \\
\text { conjunta } \\
\end{array}$ \\
\hline $\begin{array}{l}2003- \\
2006\end{array}$ & $\begin{array}{l}\text { Pró-Cuc } \\
\text { Criação da cooperativa e construção da fábrica } \\
\text { central } \\
\text { Aproximação com Slow Food } \\
\text { Primeira exportação através da AlterEco } \\
\text { Construção das minifábricas comunitárias } \\
\text { Venda para o PAA - doação simultânea } \\
\text { Participação em feiras nacionais e } \\
\text { internacionais }\end{array}$ & $\begin{array}{c}\text { Formação da Coopercuc } \\
\text { Foco na produção } \\
\text { orgânica e Fair Trade } \\
\text { Modelo descentralizado } \\
\text { de produção } \\
\text { (comunidade-mercado } \\
\text { alternativo) }\end{array}$ & $\begin{array}{l}\text { - mantêm-se as práticas } \\
\text { anteriores; } \\
\text { - gestão "externa" e mais } \\
\text { profissionalizada; } \\
\text { - consolidação da estrutura } \\
\text { organizacional e das } \\
\text { práticas cooperativistas; } \\
\text { - criação de uma identidade } \\
\text { vinculada à produção } \\
\text { orgânica e comércio justo; } \\
\text { - organização produtiva. } \\
\end{array}$ \\
\hline $\begin{array}{l}2007- \\
2010\end{array}$ & $\begin{array}{l}\text { Certificação orgânica e de Comércio Justo - } \\
\text { Exportação } \\
\text { Acesso ao PAA formação de estoques (capital } \\
\text { de giro) } \\
\text { Primeiro Festival do umbu } \\
\text { Criação da marca e identidade visual } \\
\text { GRAVETERO } \\
\text { Venda PNAE }\end{array}$ & $\begin{array}{c}\text { Expansão da Cooperativa } \\
\text { Consolidação da imagem } \\
\text { como referência na área } \\
\text { (mercado convencional } \\
\text { e alternativo Mercado } \\
\text { público) }\end{array}$ & $\begin{array}{l}\text { - maior distanciamento } \\
\text { entre corpo diretivo e } \\
\text { membros; } \\
\text { - consolidação dos } \\
\text { princípios da Cooperativa; } \\
\text { - organização para o } \\
\text { mercado; } \\
\text { - realização de um conjunto } \\
\text { de ações de marketing }\end{array}$ \\
\hline $\begin{array}{l}2011- \\
2014\end{array}$ & $\begin{array}{l}\text { Contrato com Pão de Açúcar } \\
\text { Projeto MDS, BNDES: aquisição de caminhões } \\
\text { e equipamentos para produção de farinha e } \\
\text { empacotamento de grãos. } \\
\text { Governo do Estado: construção de nova } \\
\text { unidade de beneficiamento } \\
\text { Aumento na comercialização de produtos para } \\
\text { o PAA e PNAE }\end{array}$ & $\begin{array}{c}\text { Expansão no mercado } \\
\text { interno } \\
\text { Ampliação das parcerias } \\
\text { institucionais, sobretudo, } \\
\text { governamentais } \\
\text { (Estado - mercado } \\
\text { público) }\end{array}$ & $\begin{array}{l}\text { - aumento da burocracia } \\
\text { interna devido aos contratos } \\
\text { e parcerias com o governo; } \\
\text { - estruturação de novas } \\
\text { estratégias e rotas; } \\
\text { - interiorização da } \\
\text { comercialização devido ao } \\
\text { PNAE; }\end{array}$ \\
\hline $\begin{array}{c}2015- \\
\text { atual }\end{array}$ & $\begin{array}{l}\text { Constituição da Central da Catinga } \\
\text { Inauguração fábrica nova } \\
\text { ATER para diversificação produtiva }\end{array}$ & $\begin{array}{l}\text { Foco na diversificação } \\
\text { da produção } \\
\text { (Mercado) }\end{array}$ & $\begin{array}{c}\text { - distanciamento dos } \\
\text { mercados institucionais; } \\
\text { - ampliação da visão de } \\
\text { negócios; } \\
\text { - atuação em redes de } \\
\text { comercialização regionais e } \\
\text { nacionais } \\
\text { - desenvolvimento de novas } \\
\text { atribuições como prestação } \\
\text { de serviços de ater. }\end{array}$ \\
\hline
\end{tabular}

Fonte: pesquisa de campo. Elaborado pelos autores (2017). 
Assim como na Coopercuc, a constituição da Rede Xique Xique é também originada de um grupo de mulheres em busca de alternativas de renda e a conformação das lógicas institucionais no campo, segue uma trajetória de acesso aos mercados parecida que se inicia com a comunidade, passa pelos mercados alternativos, depois tende para o Estado e mais, recentemente, tenta se orientar pelo e para o viés dos mercados alternativos, conforme pode ser analisado no quadro 2. 


\section{Quadro 2 - Eventos históricos, lógicas institucionais e práticas materiais e simbólicas} que marcaram a trajetória da Rede Xique Xique

\begin{tabular}{|c|c|c|c|}
\hline Período & Eventos & Resultados e LI & Práticas materiais e simbólicas \\
\hline $\begin{array}{c}1990- \\
1999\end{array}$ & $\begin{array}{l}\text { Retomada da luta pela Reforma } \\
\text { Agrária no Rio Grande do } \\
\text { Norte; } \\
\text { Criação do assentamento } \\
\text { Muluguzinho e do Grupo de } \\
\text { Mulheres Decididas a Vencer; } \\
\text { Constituição da Associação } \\
\text { Parceiros da Terra }\end{array}$ & $\begin{array}{l}\text { Formação feminista } \\
\text { organização comunitária e } \\
\text { produtiva }\end{array}$ & $\begin{array}{l}\text { - realização de mutirões; } \\
\text { - proximidade entre o grupo; } \\
\text { - forte participação política (fase de } \\
\text { acampamento); } \\
\text { - formação conjunta no tema do } \\
\text { feminismo } \\
\text { - aprendizagem quanto aos } \\
\text { processos produtivos. } \\
\text { - aproximação com consumidores. }\end{array}$ \\
\hline $\begin{array}{c}2000- \\
2004\end{array}$ & $\begin{array}{l}\text { Espaço de Comercialização } \\
\text { Solidária Xique Xique } \\
\text { Constituição da Rede Xique } \\
\text { Xique }\end{array}$ & $\begin{array}{l}\text { Ampliação das parcerias } \\
\text { Articulação da rede } \\
\text { (comunidade/ } \\
\text { mercado-alternativo) }\end{array}$ & $\begin{array}{l}\text { - mantêm-se as práticas anteriores; } \\
\text { - organização da produção; } \\
\text { - estruturação do formato } \\
\text { organizacional em rede; } \\
\text { - formação dos princípios } \\
\text { feministas e agroecológicos. }\end{array}$ \\
\hline $\begin{array}{c}2005- \\
2010\end{array}$ & $\begin{array}{l}\text { Constituição da Associação } \\
\text { Participação em feiras nacionais } \\
\text { Criação e fortalecimento dos } \\
\text { núcleos municipais } \\
\text { Ampliação dos núcleos para } \\
\text { outros territórios e afastamento } \\
\text { dos grupos formais }\end{array}$ & $\begin{array}{l}\text { Agroecologia } \\
\text { Aproximação com } \\
\text { movimento da Economia } \\
\text { Solidária } \\
\text { Foco nas feiras } \\
\text { (Estado/mercado } \\
\text { alternativo) }\end{array}$ & $\begin{array}{l}\text { - formalização da organização; } \\
\text { - atuação em rede } \\
\text { - incorporação de práticas formais e } \\
\text { informais de economia solidária } \\
\text { - estratégia de mercado voltada para } \\
\text { feiras livres e foco na relação com } \\
\text { consumidor } \\
\text { - consolidação dos princípios da } \\
\text { Rede }\end{array}$ \\
\hline $\begin{array}{c}2011- \\
2015\end{array}$ & $\begin{array}{l}\text { Expansão dos núcleos } \\
\text { Criação da Cooperxique } \\
\text { Projeto Cadsol } \\
\text { Projetos RN sustentável } \\
\text { Acesso ao PAA e PNAE } \\
\text { Grupo de Consumo via } \\
\text { WhatsApp } \\
\text { Fortalecimento Institucional }\end{array}$ & $\begin{array}{l}\text { Ampliação dos projetos } \\
\text { Atuação em diversas } \\
\text { instâncias de } \\
\text { representação da AF } \\
\text { Expansão os núcleos } \\
\text { Retomada do tema do } \\
\text { cooperativismo } \\
\text { (Estado/mercado- } \\
\text { alternativo) }\end{array}$ & $\begin{array}{l}\text { - iniciação nas práticas } \\
\text { cooperativistas; } \\
\text { - ampliação dos canais de } \\
\text { comercialização; } \\
\text { - forte atuação em fóruns de } \\
\text { economia solidária; } \\
\text { - co-gestão de políticas junto ao } \\
\text { setor público; } \\
\text { - aumento dos procedimentos } \\
\text { burocráticos }\end{array}$ \\
\hline $\begin{array}{c}2016- \\
\text { Atual }\end{array}$ & $\begin{array}{l}\text { Ampliação vendas PNAE } \\
\text { Estruturação do Sistema } \\
\text { Participativo de Garantia - SPG } \\
\text { para avaliação da conformidade } \\
\text { de produtos orgânicos } \\
\text { Projeto Geração Solidária } \\
\text { Inauguração da Bodega } \\
\text { Agroecológica (Manuel } \\
\text { Targino) } \\
\text { Projeto de construção da sede }\end{array}$ & $\begin{array}{l}\text { Foco nos mercados } \\
\text { Fortalecimento da } \\
\text { cooperativa } \\
\text { (mercado- } \\
\text { alternativo/mercado } \\
\text { público) }\end{array}$ & $\begin{array}{l}\text { - mantêm-se as práticas anteriores } \\
\text { voltadas para a relação com os } \\
\text { consumidores; } \\
\text { - estruturação da } \\
\text { organização mais voltada para } \\
\text { comercialização; } \\
\text { - maior autonomia dos núcleos; } \\
\text { - (re-)centralização de algumas } \\
\text { iniciativas através da Cooperxique. } \\
\text { - foco na sustentabilidade financeira } \\
\text { da rede. }\end{array}$ \\
\hline
\end{tabular}

Fonte: Pesquisa de campo. Elaborado pelos autores. (2017)

As semelhanças nas trajetórias de como as orientações de lógicas institucionais se apresentam para essas OEAFs pode ser explicada por questões do ambiente contextual e 
institucional. Ambas localizam-se na região semiárida, foram criadas no mesmo período e fazem parte do campo societal da agricultura familiar. De acordo com a teoria do isomorfismo, ao sofrerem as mesmas pressões do ambiente institucional, as organizações tendem à semelhança. Porém o que se nota na prática é uma grande diferença entre as organizações, assim como na forma com que as lógicas do nível societal se apresentam nos campos organizacionais conforme suas variações.

A incorporação dos princípios do feminismo, agroecologia e economia solidária que embasam a ação da RXX se dá conjuntamente com sua construção, sendo que um não pode ser realizar sem o outro, tal qual uma condição lógica. Assim, a rede atua com a perspectiva de que "não há Agroecologia sem feminismo" e tampouco, economia solidária que não considere a desigualdade de gênero e as condições de produção.

Tais elementos, portanto, permeiam todas as lógicas identificadas no campo organizacional da RXX, sendo, ao mesmo tempo parte da comunidade onde se situa, por meio de entidades e movimentos sociais; dimensões da variante alternativa do mercado, sobretudo a Agroecologia e Economia Solidária; e também objeto da ação estatal através de políticas públicas específicas de promoção de cada uma dessas questões.

Nesse caso, de modo geral, não é o canal de comercialização escolhido que impõe sua lógica à rede. Ao contrário, por escolher o tipo de mercado em quer atuar, como a venda direta ao consumidor, por exemplo, a RXX escolhe a qual tipo de orientação ela estará submetida. Um claro exemplo disso é priorização da venda direta, onde a legitimidade tem como fonte a confiança entre produtores e consumidores, e não a certificação, como exige outros mercados alternativos.

Analisando a lógica de mercado no setor da agricultura familiar, por exemplo, identificou-se a variante correspondente aos mercados alternativos, caracterizados, no contexto analisado, pelo forte vínculo com a Agroecologia e Economia Solidária. A forma, no entanto, com que estes elementos se apresentam em cada campo organizacional ou OEAF analisada pode variar de acordo com a história, com o contexto social ou, mesmo, a partir do tipo de interpretação dada ao fenômeno.

No caso da Economia Solidária, identificou-se que, enquanto na Coopercuc, ela se apresenta partir de seu componente mais vinculado ao comércio justo - que foca na relação de troca entre países, onde consumidores do norte, movidos pelo princípio da justiça social, 
ajudam produtores do sul -, na RXX, se apresenta como uma ferramenta que privilegia as relações locais. Tal diferença é explicada ao se analisar a história de cada organização.

Enquanto a Coopercuc iniciou sua trajetória na economia solidária através das exportações para o comércio justo, a partir do incentivo da cooperação alemã, a RXX adotou esse mesmo mote como estratégia orientada para a venda direta, privilegiando a aproximação entre produtores e consumidores através de canais como as feiras. Esse exemplo em particular mostra que as lógicas podem mudar não somente de acordo com os campos e organizações, mas também com relação aos elementos que a compõe.

\section{CONSIDERAÇÕES FINAIS}

As crescentes pressões do ambiente competitivo global obrigam cada vez mais os agricultores a buscarem soluções inovadoras, motivando a recente onda de criação de cooperativas, associações e redes de comercialização que buscam produzir novidades a partir de arranjos organizativos diferenciados, da agregação de valor às matérias primas e da construção de mercados alternativos. Neste sentido, o presente trabalho buscou fornecer elementos que ajudem a analisar o papel que ocupam os arranjos organizacionais mobilizados pelos agricultores familiares em sua relação com os mercados.

Com isso, se buscou identificar quais são as lógicas institucionais que orientam a relação das organizações econômicas da agricultura familiar com os mercados, fundamentando-se na hipótese de que tal processo é mediado por práticas materiais e construções simbólicas, a partir da proposta teórico-metodológica da Lógica Institucional, segundo a qual os interesses, identidades, valores e pressupostos dos indivíduos e organizações estão inseridos dentro de lógicas institucionais prevalecentes, sendo que as decisões e seus resultados se dão pela intersecção entre a agência individual e a estrutura institucional.

A partir da análise dos casos, considerando a contingência histórica, elementos do ambiente técnico e institucional, assim como especificidade do contexto social e da configuração do campo organizacional, identificou-se a influência das lógicas institucionais do mercado, Estado e comunidade, além de híbridos entre elas e variantes, a partir das fontes de identidade, de autoridade e legitmidade, e os fundamentos da atenção, das normas e das estratégias que orientam a tomada de decisão. 
O principal achado da pesquisa, no entanto, refere-se à compreensão de como uma mesma lógica institucional pode se apresentar de forma diferente e, até contraditória, a depender não apenas do nível de análise, mas também do contexto, da história e da forma como seus elementos são percebidos e interpretados, podendo incorrer ou não em uma mudança.

\section{REFERÊNCIAS}

ABRAMOVAY, R. Paradigmas do capitalismo agrário em questão. São Paulo: Anpocs/Unicamp; Hucitec, 1992.

BARDIN, Lawrence. Análise de conteúdo. Lisboa: Edições 70, 1979.

ELLIS, F. Peasant Economies. Farm households and agrarian development. Cambridge, 1988.

FRIEDLAND, R.; ALFORD, R.R. Bringing society back in: symbols, practices, institutional contradictions. In: POWELL, W. W.; DIMAGGIO, P.J. (Eds.). The new institutionalism in organizational analysis. London: University of Chicago Press, 1991. P.232-263.

MALUF, Renato. Abastecimento Alimentar no Brasil, 2012. Disponível em: $<$ http://www4.planalto.gov.br/consea/eventos/plenarias/apresentacoes/2012/apresentacao03-novembro-2012>. Acesso em: 30/06/2015.

MINAYO, Maria. C. S (Org.). Pesquisa social: teoria, método e criatividade. Petrópolis, RJ: Vozes, 2001. p.09-29.

MINAYO, Maria Cecília de Souza. O desafio da pesquisa social. Pesquisa social: teoria, método e criatividade, v. 28, p. 9-29, 2007.

PELLEGRINI, G.; GAZOLLA, M. A agroindústria familiar no Rio Grande do Sul: limites e potencialidades a sua reprodução social. Frederico Westphalen: URI, 2008.

PLOEG, Jan Douwe Van der. Camponeses e Impérios Alimentares: lutas por autonomia e sustentabilidade na era da globalização. Porto Alegre: Editora da UFRGS, 2008.

SCHMITT, Claudia J.; MALUF, Renato S. Soberania e segurança alimentar no Mercosul Ampliado: o lugar da agricultura camponesa e familiar.Interpretações, estudos rurais e política. R. Janeiro, EDUR/Mauad X, v. 133, p. 155, 2010.

THORNTON, Patricia H.; OCASIO, William; LOUNSBURY, Michael. The institutional logics perspective. Oxford: Oxford Press, 2012. 